\title{
A GESTÃO DO PROCESSO EDUCACIONAL DA PESSOA COM DEFICIÊNCIA: a legislação e a formação do professor
}

\section{LÚCIO JORGE HAMMES (UNIPAMPA)}

Doutor em Educação pela UNISINOS. Coordenador do Programa de Pós-Graduação em Educação da Universidade Federal do Pampa. Líder do Grupo de Pesquisa Cultura Escolar, Práticas Pedagógicas e Formação de Professores. ORCID: https://orcid.org/0000-0003-06584628 E-mail: 1uciojh@gmail.com

\section{BENTO SELAU (UNIPAMPA)}

Doutor em Educação em Educação pela UFPEL. Coordenador do Programa de Pós-Graduação em Educação da Universidade Federal do Pampa. Professor do Programa de Pós-Graduação em Educação da Universidade Federal do Pampa. Líder do Grupo de Pesquisa Educação Inclusiva e Defectologia de Vygotski. ORCID https://orcid.org/0000-0002-5792-0284:

E-mail: bentoselau@gmail.com 


\title{
LUCIANE LAKUS RONCATO (UNIPAMPA)
}

\author{
Mestre em Educação pela UNIPAMPA. Professora da Rede Pública Municipal \\ de Pelotas, Rio Grande do Sul. ORCID https://orcid.org/0000-0003-0332-4257 \\ E-mail: luciane.roncato@outlook
}

\begin{abstract}
RESUMO
Este artigo traz resultados de um processo de pesquisa e intervenção que teve como objetivo qualificar o processo de gestão educacional na Escola Especial José Luiz Piúma das pessoas com deficiência em Jaguarão, Rio Grande do Sul. Os estudos partiram das leis referentes à educação especial no Brasil, leituras de Paulo Freire e seus pressupostos teóricos. A metodologia utilizada foi a intervenção pedagógica, desenvolvida através de cinco encontros em que os professores refletiram, dialogaram e aprofundaram conhecimentos, em busca de alternativas para qualificar o processo educacional. Os achados evidenciaram que os professores se sentem capazes para aprimorar sua prática, identificando problemas, apontando soluções e agindo quando lhes couber resolver.
\end{abstract}

PALAVRAS-CHAVE: Educação inclusiva. Pessoa com deficiência. Gestão do processo educacional. Formação de professores.

\section{THE MANAGEMENT OF THE EDUCATIONAL PROCESS OF THE DISABLED PERSON: the legislation and the training of the teacher}

This article presents results of a research and intervention process that aimed to qualify the process of educational management in the Special School José Luiz Piúma of people with disabilities in Jaguarão, Rio Grande do Sul. The studies were based on the laws regarding special education in Brazil, readings by Paulo Freire and their theoretical assumptions. The methodology used was the pedagogical intervention, developed through five meetings in which teachers reflected, dialogued and deepened knowledge, in search of alternatives to qualify the educational process. The findings showed that teachers feel capable of improving their practice, identifying problems, pointing out solutions and acting when they can solve them.

Keywords: Inclusive education. Disabled person. Management of the educational process. Teacher training. 


\section{LA GESTIÓN DEL PROCESO EDUCACIONAL DE LA PERSONA CON DISCAPACIDAD: la legislación y la formación del profesor}

Este artículo trae resultados de un proceso de investigación e intervención que tuvo como objetivo calificar el proceso de gestión educativa en la Escuela Especial José Luiz Piúma de las personas con discapacidad en Jaguarão, Rio Grande do Sul. Los estudios partieron de las leyes referentes a la educación especial en Brasil, lecturas de Paulo Freire y sus presupuestos teóricos. La metodología utilizada fue la intervención pedagógica, desarrollada a través de cinco encuentros en que los profesores reflexionaron, dialogaron y profundizaron conocimientos, en busca de alternativas para calificar el proceso educativo. Los resultados evidenciaron que los profesores se sienten capaces de perfeccionar su práctica, identificando problemas, apuntando soluciones y actuando cuando les cabe resolver.

Palabras Clave: Educación inclusiva. Persona con discapacidad. Gestión del proceso educativo. Formación de profesores.

\section{A GESTÃO DO PROCESSO EDUCACIONAL DA PESSOA COM DEFICIÊNCIA: a legislação e a formação do professor}

Este trabalho constitui-se em recorte de uma pesquisa e intervenção que teve como objetivo qualificar o processo de gestão educacional na Escola Especial José Luiz Piúma das pessoas com deficiência em Jaguarão/RS. A escola é uma Associação de Pais e Amigos dos Excepcionais APAE, que faz parte da rede das APAEs que tem sua origem em 1954 e se constituem em uma organização social, cujo objetivo principal é promover a atenção integral à pessoa com deficiência intelectual e múltipla.

Inquietados com os rumos da Educação Especial no cenário da perspectiva inclusiva, a escola propôs uma formação que, com a orientação do Mestrado Profissional em Educação da Unipampa se constituiu uma intervenção pedagógica, uma extensão universitária no formato de oficinas que permitiram aprofundar questões político-pedagógicas acerca de aspectos legais e das práticas educativas da educação especial. No desenvolvimento do trabalho apareceram preocupações observadas no contexto escolar, compartilhadas com nossos pares no trabalho docente, com relação ao processo inclusivo.

A legislação referente à Educação Especial utiliza a terminologia, preferencialmente, ao se referir à matrícula para pessoas com deficiência, transtornos globais do desenvolvimento e 
altas habilidades ou superdotação em escolas comuns (BRASIL, 1996; 2010; 2014). Neste artigo usaremos a expressão "escola comum", de acordo com o Decreto n 3.956 de 2001 ao afirmar que,

A educação escolar de alunos que apresentam necessidades educacionais especiais e que requeiram atenção individualizada nas atividades da vida autônoma e social, bem como ajudas e apoios intensos e contínuos e flexibilizações e adaptações curriculares tão significativas que a escola comum não tenha conseguido prover - pode efetivar-se em escolas especiais, assegurando-se que o currículo escolar observe as diretrizes curriculares nacionais para as etapas e modalidades da Educação Básica e que os alunos recebam os apoios de que necessitam (BRASIL, 2001, p. 54).

Ainda parece haver compreensão equivocada por parte de alguns educadores e gestores das escolas comuns; assim como de algumas famílias das pessoas com deficiência sobre a obrigatoriedade da matrícula nestas escolas comuns, manifestando, inclusive, o receio de processo judicial ou multa. Por outro lado, manifesta preconceito latente nas relações sociais e do provável despreparo destas instituições escolares para atendimento especializado a cada caso de deficiência identificado.

Compartilhamos a concepção de que as práticas educativas, as escolhas teóricometodológicas, as características e necessidades discentes são diferenciadas, requerendo especificidades no atendimento educacional. Os casos de cada aluno, ou grupo destes, evidenciam deficiências que não podem ser consideradas iguais, exigindo, portanto, atenção, planejamento e ações específicas aos casos devidamente diagnosticados. Porém, interpretações da legislação podem gerar equívocos que ainda causam polêmicas para o processo de inclusão da pessoa com deficiência, principalmente, a inclusão escolar, quando for considerado que deva abranger todos os alunos, não especificando tipo ou grau de deficiência.

\section{Conforme o Art. 58 da LDB,}

Entende-se por educação especial, para os efeitos desta Lei, a modalidade de educação escolar oferecida preferencialmente na rede regular de ensino, para educandos com deficiência, transtornos globais do desenvolvimento e altas habilidades ou superdotação. (BRASIL, 1996).

O Plano Nacional de Educação (BRASIL, 2014), preparado nas Conferências Municipais, Estaduais e Nacional envolveu muitos educadores, especialmente de 2011 a 2014, sendo aprovado e sancionado para o decênio de 2014 a 2024. O Plano prevê na meta 4, 
Universalizar para a população de quatro a dezessete anos, o atendimento escolar aos alunos com deficiência, transtornos globais do desenvolvimento e de altas habilidades ou superdotação, preferencialmente na rede regular de ensino, garantindo o atendimento educacional especializado em salas de recursos multifuncionais, classes, escolas ou serviços especializados, públicos ou comunitários, nas formas complementar e suplementar, em escolas ou serviços especializados, públicos ou conveniados (BRASIL 2014).

Houve, inclusive, uma repercussão, conhecida como o "movimento contra a inclusão radical" e ocorreu quando o PNE tramitava no Congresso Nacional para aprovação o seguinte texto da meta 4 do PNE: "Universalizar, para população de 4 a 17 anos, o atendimento escolar aos estudantes com deficiência, transtornos globais do desenvolvimento e altas habilidades ou superdotação na rede regular de ensino". No texto é tirada a palavra "preferencialmente", que poderia trazer consequências de grande complexidade aos envolvidos com a educação especial no Brasil.

Noronha e Pinto (2011) conceituam a educação especial como sendo uma modalidade da educação organizada para atender específica e exclusivamente alunos com determinadas necessidades especiais, dizendo que algumas escolas se dedicam apenas a um tipo de necessidade, enquanto outras se dedicam a vários.

Conforme os autores (NORONHA; PINTO, 2011) a Educação Especial ainda tem sido alvo de críticas por não promover o convívio entre os alunos especiais e os demais alunos. Por outro lado, a escola direcionada para a educação especial conta com materiais, equipamentos e professores especializados, além de equipe técnica multiprofissional - psicólogo, fisioterapeuta, fonoaudiólogo, terapeuta ocupacional, entre outros. O sistema de ensino comum precisa ser adaptado e pedagogicamente transformado para atender de forma inclusiva.

Provocados pela perspectiva da legislação da educação inclusiva e sua operacionalização (BRASIL, 1996; 2012; 2014), bem como, dos estudos sobre a temática encontramos elementos teórico-práticos para buscar alternativas de ação.

Para conhecer melhor a situação da educação das pessoas com deficiência, foram realizadas, ainda, visita à quatorze escolas da zona urbana do município de Jaguarão/RS, de ensino público. O objetivo das visitas foi confirmar a dupla matrícula de alunos que naquele período frequentavam a escola especial e escola comum para dados do censo escolar. Em diálogo com as direções e professoras do atendimento educacional especializado (AEE) obteve-se a informações de que, em geral, são aceitas em suas escolas as matrículas de alunos com deficiência pelo cumprimento 
da lei. Contudo, sentiam falta de condições para o atendimento adequado, devido à falta de profissionais habilitados para as aulas e atendimentos dos alunos especiais. Além de não disporem de espaço físico, material didático e pedagógico adequados ao atendimento especializado.

Desta forma, com base em pressupostos teóricos de Freire (2002), e tendo como eixo a legislação que dá base a práticas de educação especial no Brasil, se fundamentou um projeto de intervenção com o objetivo de qualificar o processo de gestão educacional na Escola Especial José Luiz Piúma das pessoas com deficiência em Jaguarão/RS, através da formação docente. Especificamente, buscou-se acompanhar o processo da organização do Plano Nacional de Educação, através de leitura e análise das proposições legais e a repercussão junto a órgãos específicos e setores interessados no tema. Foram realizados estudos sobre a educação especial, através de oficinas, encontros de formação na própria escola e em eventos científicos com apresentação de trabalho sobre a temática.

A formação proposta como Extensão Universitária, tratou-se de aprimorar a formação permanente no trabalho, favorecendo a criação e manutenção do ambiente de diálogo entre os professores, oportunizando: a) a socialização de ideias e inquietações referentes ao cotidiano de cada um; b) a troca de experiências; c) as problematizações; d) a construção de conhecimentos e, e) a busca de aperfeiçoamento da qualidade educacional, provocando mudanças com uma fundamentação teórica que contribuísse com a prática pedagógica desenvolvida.

A seguir, apresentamos a metodologia utilizada, aprofundando os achados da pesquisa e elencando algumas considerações finais.

\section{Método - Intervenção}

A intervenção aqui relatada buscou a construção coletiva de um espaço-tempo de reflexões na escola, focalizando a formação docente no âmbito das políticas de educação especial, tomando como referência as mudanças ocorridas na legislação. Discute sua repercussão no meio educacional e a reação de professores diante destas circunstâncias que afetaram de forma explícita ou tácita sua ação junto aos alunos e os ajustes na relação com outras instituições relacionadas a esta modalidade de ensino. Para tanto, foram propostos e realizados encontros, com vistas a analisar e socializar construções de saberes docentes, a partir de discussões sobre as mudanças que envolveram a educação especial, sua dinâmica, características e a legislação pertinente e atual. 
A intervenção teve como objetivo geral qualificar o processo de gestão educacional na Escola Especial José Luiz Piúma das pessoas com deficiência em Jaguarão/RS, através da formação docente; e como objetivos específicos: - acompanhar o processo da organização do Plano Nacional de Educação, através de leitura e análise das proposições legais e a repercussão junto a órgãos específicos e setores interessados no tema; - realizar estudos sobre a educação especial, com leituras, discussões e trabalhos individuais e grupais, proporcionados pelas oficinas do projeto; - dialogar com educadores comprometidos com a educação especial e educação inclusiva, a partir de encontros de formação permanente na Escola Especial José Luiz Piúma e em eventos extraescolares, na Universidade ou em outros âmbitos acadêmicos.

A discussão ocorreu na própria escola em que atuam o professores da educação especial. Propiciou a reconstrução do cotidiano de trabalho e ajudou a lançar um olhar crítico aos movimentos da política de educação especial nos últimos anos.

A carência de debate pedagógico e de discussões acerca do trabalho do professor, assim como a importância de aliar teoria e prática à reflexão sobre qual a educação especial os docentes que trabalham com dedicação, competência e grande entusiasmo na interação com os discentes acreditam desenvolver e qual o trabalho pretenderiam desenvolver a partir dos debates nos encontros com pares na profissão que exercem, foi um elemento presente nas falas dos participantes dos grupos de trabalho.

Desta forma, explicita-se que o procedimento metodológico proposto para este estudo é a intervenção desenvolvida na Escola Especial José Luiz Piúma/APAE, utilizando como método de ensino para intervenção a educação popular de Freire como referencial para a formação permanente.

\section{Resultados e Discussão}

O curso de extensão universitária, no formato de oficinas na perspectiva freireana possibilitou qualificar o processo de gestão educacional na Escola Especial José Luiz Piúma das pessoas com deficiência em Jaguarão/RS, através da formação docente. Os objetivos específicos previam acompanhar o processo da organização do PNE, através de leitura e análise das proposições legais e a repercussão junto a órgãos específicos e setores interessados no tema; realizar estudos sobre a educação especial, com leituras, discussões e trabalhos individuais e grupais, proporcionados pelas oficinas do projeto; dialogar com educadores comprometidos com a educação especial e educação inclusiva, a partir de encontros de formação permanente na 
Escola Especial José Luiz Piúma e em eventos extraescolares, na Universidade ou em outros âmbitos acadêmicos.

As ações para oportunizar encontros para discutir e favorecer a formação permanente no local de trabalho, reivindicadas pelos professores da escola foram destacas como importantes. A intervenção proporcionou o espaço para dialogar, refletir e compartilhar inquietações, construindo conhecimento a partir da experiência profissional de cada um, fornecendo subsídios para fundamentar teoricamente a prática docente.

O processo dialógico sustentado por Paulo Freire (2002), garantiu que todos participantes se envolvessem, tendo "voz e vez" para se expressarem, discutirem. Apontaram sugestões para qualificar o processo educacional das pessoas com deficiência intelectual e/ou múltipla na escola e também no processo inclusivo no município de Jaguarão/RS.

Destaca-se o processo dialógico, tendo a perspectiva de continuidade almejada e manifestada pelos participantes dos encontros. Busca defender ideias com argumentações, evidenciando as contradições e fazendo emergir novas ideias que prevalecerão. A abrangência deste trabalho, no que se refere ao aprofundamento teórico acerca das concepções teóricas e seus princípios concentraram-se na construção do espaço de reunião de esforços, saberes, trocas, leituras e estudos, enfim, diálogo, socializando conhecimentos e convergências de ideias sobre a educação especial, baseada na legislação específica, teóricos reconhecidos e nas práticas pedagógicas a serem desenvolvidas.

Desta forma, o projeto de intervenção, construído com aos professores, tendo por base pressupostos teóricos de Freire, teve como eixo articulador a legislação que dá base a práticas de educação especial no Brasil. Dessa forma buscou-se aprimorar a formação permanente de docentes no local de trabalho, favorecendo a criação e manutenção de um espaço para,

1) Diálogo com os professores, fazendo emergir e socializar suas principais inquietações referentes à práxis de cada um e de todos;

2) Troca de experiências docentes;

3) Problematizações feitas e debatidas pelos professores;

4) Construção de conhecimentos docentes ao longo da intervenção;

5) Busca de aperfeiçoamento da qualidade educacional provocando mudanças na articulação de fundamentação teórica e práticas pedagógicas. 
Destacam-se percepções, conteúdos, expectativas e atitudes que foram manifestadas nos encontros na intervenção, ou a partir deles. Portanto, no relato das expressões emergentes das reuniões com os professores são evidenciados os resultados da intervenção proposta e desenvolvida:

\title{
3.1 Inquietações referentes à práxis educativa
}

Ao dialogar, refletir e compartilhar inquietações, construindo conhecimento a partir da experiência profissional, cada um dos participantes buscou subsídios para fundamentar teoricamente a prática docente. Dessa forma, a intervenção desencadeou o processo dialógico proposto por Paulo Freire. Provocou aos participantes "dizer a sua palavra" e, neste espaçotempo a se manifestarem, debaterem. Sugeriram, por consenso, o aprimoramento da formação pedagógica e do processo educacional das pessoas com deficiência intelectual e/ou múltipla na escola. O processo dialógico foi o ponto forte desse trabalho. Desafiando, refletindo, construindo e reconstruindo, motivando, compartilhando e solidarizando conforme preconiza Damiani,

\begin{abstract}
A revisão das investigações acerca do trabalho colaborativo - em suas diferentes formas - assim como o entendimento do processo que o sustenta sugerem que esse tipo de atividade apresenta potencial para auxiliar no enfrentamento dos sérios desafios propostos pela escola atual em nosso país. A literatura indica que o desenvolvimento de atividades de maneira colegiada pode criar um ambiente rico em aprendizagens acadêmicas e sociais tanto para estudantes como para professores, assim como proporcionar a estes um maior degrau de satisfação profissional. $\mathrm{O}$ trabalho colaborativo possibilita, além disso, o resgate de valores como o compartilhamento e a solidariedade (DAMIANI, 2008, p. 224/225).
\end{abstract}

As principais inquietações foram referentes à própria intervenção, pois foi proposta, por unanimidade, a continuidade mais aprofundada e ampliada desse espaço de diálogo e de formação permanente. Conforme a carta final dirigida à presidente da APAE.

\subsection{Partilha da prática docente}

As atividades de trocas de experiências promovidas nos encontros com os professores permitiram esclarecer concepções sobre legislação, currículo e sobre o ensinar e o aprender na educação especial. Foram valorizados os momentos de aprendizagem na comunicação com o outro. Nesta comunicação, o sujeito e o outro foram vistos reciprocamente como profissionais 
dedicados a atingir objetivos comuns na escola e no desenvolvimento da cidadania discente, negociando significados e reconhecendo a importância de ampliar seu saber sobre as pessoas, bem como sobre concepções e práticas pedagógicas que desenvolvem ou propõem. Nessa interação e no contato com a legislação e com base teórica pertinente foi possível identificar, distinguir e utilizar diversas maneiras de aprender e ensinar. Na socialização das concepções, conhecimentos, práticas exercidas, angústias, dúvidas, descontentamentos e satisfações nas ações docentes, é interessante que se considere que,

Existe ainda muito pouca ênfase sobre a reflexão como uma prática social que acontece em comunidades de professores que se apoiam mutuamente e em que um sustenta o crescimento do outro. Ser desafiado e, ao mesmo tempo, apoiado por meio da interação social é importante para ajudar-nos a clarificar aquilo que nós acreditamos e para ganharmos coragem para perseguir nossas crenças (ZEICHNER, 2008, p. 543).

De maneira geral, os professores foram participativos e espontâneos. Houve envolvimento e postura que demonstraram apoio mútuo nas leituras dos textos, nas conversas, no compartilhamento de ideias. Nos momentos de formação de duplas ou grupos maiores (dois grupos) e até mesmo na socialização no grande grupo, os professores participantes se sentiram à vontade para trazer suas experiências, relatando casos específicos de alunos e/ou famílias destes. Por vezes, pareciam desabafos de angústias. Esta abertura à participação constituiu em momentos ricos de reflexões da prática docente, associada às temáticas dos encontros. Os diálogos nos pequenos grupos e a socializadas na grande roda contribuíram para a criação desse espaço que a escola tem o desafio para mantê-lo no calendário escolar.

Durante a intervenção, os espaços de diálogo permitiram aos professores expressarem suas inquietações, frustrações e também suas conquistas com alunos, com pais, no próprio ambiente de trabalho, com e entre colegas. Assim, logo após a primeira oficina, um professor expressou:

Nunca tivemos essa oportunidade antes, de discutir assim dessa maneira, já tinha escutado falar de Paulo Freire, mas não tinha lido nenhuma de suas obras, hoje vejo o como é fundamental ler e conhecê-lo melhor. Todos os professores deveriam conhecê-lo assim como nós tivemos essa oportunidade. 
Outra professora, participante desta oficina, falando dos aprendizados desenvolvidos, desabafou: "o que adianta colocar a criança numa escola que aparentemente oferece atendimento em turno integral só para ficar passeando de braço dado com a cuidadora".

Em outros momentos houve trocas de sugestões de planejamentos, de atividades com os alunos e foram debatidas questões referentes à falta de higiene e participação da família. Em relação aos processos de aprendizagens para os alunos com deficiência intelectual as professoras discutiram a importância do material concreto, da informática, do lúdico, da psicomotricidade como ferramentas de apoio.

Certamente esse espaço propiciou uma aproximação maior dos colegas, reforçando a ideia expressa por Perrenoud de que,

Pensar a prática não é somente pensar a ação pedagógica na sala de aula nem, mesmo a colaboração didática com os colegas. É pensar a profissão, a carreira, as relações de trabalho e de poder nas organizações escolares, a parte da autonomia e de responsabilidade conferida aos professores individual ou coletivamente. [...] No quadro de profissionalização, mais do que difundir respostas e soluções, a formação prepara os futuros professores para se interrogarem e para identificarem e resolverem problemas. Confere, portanto competências metodológicas, não, sobretudo para ensinar, mas para refletir sobre a prática de cada um (PERRENOUD, 1993, p. 200).

\subsection{Problematizações dos professores}

Durante as discussões muitas foram as questões levantadas pelos participantes em relação à educação especial e ao processo inclusivo. Refletiram sobre suas práticas pedagógicas, fizeram leituras de textos, se apropriaram da legislação da educação especial, perceberam a importância da teoria, discutiram o contexto da educação especial e inclusivo e nos debates apontaram problemáticas a serem percorridas.

Este grupo entende que hoje a legislação também é uma das problematizações para que ocorra o processo inclusivo de qualidade, devido a sua abrangência e interpretação.

O grupo constata a distância entre o que a legislação já traz e sua operacionalização. 


\subsection{Construção de saberes docentes}

Ao longo da intervenção os professores participantes foram apropriando-se dos conhecimentos das leis referentes à educação especial (CF, LDB, PNE, Lei Orgânica Municipal; das DCN, currículo para escola especial, PPP), além de concepções de educação especial, educação inclusiva associando aos pressupostos teóricos de Paulo Freire. No diálogo e na reciprocidade construímos e reconstruímos conhecimentos:

(...) qualquer relação com o saber comporta também uma dimensão de identidade: aprender faz sentido por referência à história do sujeito, às suas expectativas, às suas referências, à sua concepção da vida, às suas relações com os outros, à imagem que tem de si e à que quer dar de si aos outros. Toda relação com o saber é também relação consigo próprio: através do "aprender", qualquer que seja a figura sob a qual se apresente, sempre está em jogo a construção de si mesmo e seu eco reflexivo, a imagem de si (CHARLOT, 2000, p. 17).

Nas conversas iniciais os participantes diziam conhecer a legislação principalmente, o PNE. A intervenção permitiu ampliar os conhecimentos e todos tiveram a oportunidade de aprofundar mais os conhecimentos. No final, foi solicitado à continuidade dos estudos manifestando também o interesse de ampliar as oficinas para as escolas públicas discutindo as temáticas propostas na intervenção e também buscar outras temáticas.

O processo dialógico construído na intervenção motivou os professores para se expor, participar, questionar, opinar, trocar ideias e experiências, como indica Freire:

Minha segurança se funda na conviç̧ão de que sei algo e de que ignoro algo a que se junta a certeza de que posso saber melhor o que já sei e conhecer o que ainda não sei. Minha segurança se alicerça no saber confirmado pela própria experiência de que, se minha inconclusão, de que sou consciente, atesta, de um lado, minha ignorância, me abre, de outro, o caminho para conhecer (FREIRE, 2002, p.153).

Tal motivação impulsionou alguns professores a buscarem a continuidade da formação em cursos em longo prazo, participando de processos seletivos em especializações na UNIPAMPA, a partir da intervenção, corroborando ao que diz Giesta (2005, p. 67), 
O crescimento intelectual, moral, crítico, político e profissional do professor favorece sua valorização, seu entendimento, sua participação mais efetiva, levando-o a uma visão da realidade mais ampla e a uma visão de si e de sua história melhor orientada, assim como a um engajamento numa proposta de mudança social.

Nesse sentido, todos foram provocados a sair da zona de conforto em busca de qualificação profissional para cada vez mais qualificar o processo das aprendizagens das pessoas com deficiência intelectual e/ou múltipla. Tal perspectiva corrobora com Giesta (2005) ao defender que o professor deve articular um espaço e tempo de trabalho e espaço e tempo de formação para que se estruturem as dimensões político-sócio-técnicas da ação pedagógica, valorizando a capacidade de decisão docente no confronto de situações diversas e complexas do cotidiano escolar (GIESTA, 2005, p. 67).

\subsection{Busca de aperfeiçoamento na práxis pedagógica}

O processo de intervenção, e em todas as etapas de seu desenvolvimento, instigou os professores participantes a pesquisar e a intervir, revendo conceitos e afirmando a importância da educação especial. Oportunizou espaços de aprofundamento de conceitos sobre educação especial e educação inclusiva na perspectiva de uma educação popular, provocando debates e ampliando horizontes no sentido de buscar complementaridade entre a educação especial como aliado no processo inclusivo. Assim, convergiu à ideia de que,

Não há ensino sem pesquisa e pesquisa sem ensino. Esses que fazeres se encontram um no corpo do outro. Enquanto ensino, continuo buscando, reprocurando. Ensino porque busco, porque indaguei, porque indago e me indago. Pesquiso para constatar, constatando; intervenho, intervindo; educo e me educo. Pesquiso para conhecer o que ainda não conheço e comunicar ou anunciar a novidade (FREIRE, 2002, p. 32).

As discussões e os estudos levaram à constatação da importância da educação especial para o processo inclusivo. Não ir contra as leis, mas fazer uma inclusão séria, comprometida, com as condições que indicam a qualificação do processo, atendendo as necessidades dos educandos incluídos. Não permitir uma inclusão que exclua, conforme Correia (2003). Para este autor, há crianças que, num dado momento das suas vidas, pode necessitar de serviços de educação especial, que podem estar completamente fora dos limites da classe regular (CORREIA, 2003, p. 
102). Desta forma, as APAEs podem contribuir no processo de educação inclusiva, levando em conta que,

(...) no entusiasmo da adesão à política de Educação Inclusiva, têm se observado em muitas redes escolares um enfraquecimento ou mesmo descontinuidade dos serviços educacionais especializados, com resultados nem sempre satisfatórios no que se refere ao processo de ensino-aprendizagem de alunos com necessidades educacionais especiais. Portanto, é preciso muita cautela na implementação de uma transformação radical e imediata do sistema educacional, antes de um acúmulo de experiências sistemáticas que permitam uma análise crítica do processo no contexto macro das políticas educacionais e, sobretudo, no contexto micro do cotidiano escolar (BUENO, 2006; PLETSCH e FONTES, 2006; FERREIRA, 2006; GLAT e BLANCO; 2007). A Educação Inclusiva tem que ser vista como um processo progressivo, dinâmico e contínuo, que pressupõe a adaptação do sistema escolar e de cada instituição, acompanhada de uma mudança da cultura escolar para aceitar a diversidade de estilos e ritmos de aprendizagem entre seu alunado (GLAT; PLETSCH; FONTES, 2007, p. 350).

Destacam-se os conhecimentos construídos pelos professores sobre a legislação da educação especial, na procura daquilo que acreditam e lutam para garantir os direitos da escola especial e do atendimento mais adequado às pessoas com deficiência intelectual e/ou múltipla. A busca por subsídios que amparem o trabalho docente, manifestado ao solicitarem para continuar com a formação permanente no próprio ambiente escolar e ampliando as oficinas para as escolas de ensino público é também relevante e motivador.

Esta intervenção, o ambiente de estudo, discussão, reflexão docente foi favorável a novas buscas de saberes pelos professores participantes que, em curto, médio ou longo prazo, querem dar continuidade à sua formação acadêmica.

A partir das manifestações expostas durante a intervenção os professores cada vez mais querem se sentir capazes para:

- fazer educação aprimorando sua qualidade;

- desenvolver um ensino melhor junto a seus alunos na educação especial, identificando 
problemas, apontando soluções e agindo quando lhes couber resolver;

- atentar e reivindicar ações eficazes junto às demais instituições e a todos os setores da sociedade responsáveis pelo contexto político-social da educação de todos, de maneira digna e respeitosa por suas especificidades, procurando impedir que seus alunos sejam excluídos de um processo educativo compatível às suas necessidades e às da sociedade na qual vivem.

Assim, as repercussões da intervenção demonstraram-se importantes como um começo de um longo caminho a ser seguido. Todos foram provocados e agora tem um compromisso desafiador que instiga a continuar essa caminhada.

\section{Considerações Finais}

Este artigo constitui-se em um recurso para que educadores e gestores possam refletir e repensar sobre o processo de inclusão escolar. Não tem a pretensão de mudar os olhares de todos os educadores. Os dados apresentados vão em direção a uma escola que não exclui a outra. $\mathrm{E}$ a educação especial pode ser uma importante aliada no processo de inclusão escolar na rede comum de ensino.

O atual cenário da política educacional é voltado para perspectiva inclusiva, amparando a diversidade, com leis abrangentes, causando distorções e interpretações diversas. Por isso, é importante que os educadores se apropriem de conhecimentos relacionados à sua prática, busquem subsídios e encaminhem condições para a formação permanente.

O que emergiu nas discussões com os participantes da intervenção é de continuar a formação na própria escola e ampliar a formação para as outras escolas, buscando aprofundar os conhecimentos para desenvolver um trabalho coletivo, responsável e comprometido.

O processo dialógico, construído junto aos professores, possibilitou discussões acaloradas tendo por base as contribuições de Paulo Freire. A educação popular utilizada na intervenção ajudou a desenvolver um trabalho com os participantes, sendo partícipes, com "voz e vez" para relatar suas experiências, trocar ideias, refletir, pensar e repensar suas práticas em busca de fortalecer e qualificar o processo de aprendizagem das pessoas com deficiência intelectual e/ ou múltipla, de acordo com a legislação. 
O trabalho dialógico, durante a intervenção na Escola Especial José Luiz Piúma, foi marcado por momentos ímpares de crescimento pessoal e compromisso profissional, destacados com repercussões positivas, superando os problemas encontrados, discutidos nesse processo.

\section{REFERÊNCIAS}

BRASIL. Ministério da Educação. Diretrizes Nacionais para a Educação Especial na Educação Básica. Brasília, DF, 2001. Disponível em <http://portal.mec.gov.br/seesp/arquivos/pdf/ diretrizes.pdf $>$. Acesso em mar. 2018.

BRASIL, Presidência da República. Convenção Interamericana para a Eliminação de Todas as Formas de Discriminação contra as Pessoas Portadoras de Deficiência. Brasília, DF, 2001.

BRASIL, Presidência da República. Estabelece as diretrizes e bases da educação nacional. Brasília, DF, 1996. Disponível em: <http://www.planalto.gov.br/Ccivil_03/leis/L9394.htm>. Acesso em 2018.

BRASIL. LDB. Lei de Diretrizes e Bases da Educação Nacional. MEC/Brasília, 2005. Disponível em: $<$ http://www2.senado.leg.br/bdsf/bitstream/handle/id/70320/65.pdf?sequence=3>. Acesso em maio de 2017.

BRASIL. Plano Nacional de Educação (PNE) 2014-20124 (Lei n ${ }^{\circ} 13005$ de 25 de Junho de 2014). Disponível em: <www.planalto.gov.br/ccivil_03/_ato2011-2014/2014/lei/113005.htm>. Acesso em: 26 Out. 2016.

CHARLOT, Bernard. O saber e as figuras do aprender. In: CHARLOT, Bernard. Da relação com o saber: elementos para uma teoria. Tradução de Bruno Magne. Porto Alegre: Artes Médicas, 2000 .

CORREIA, Luís de Miranda. Educação especial e inclusão: Quem disser que uma sobrevive sem a outra não está no seu juízo perfeito. Porto Editora. Portugal, 2003.

DAMIANI, Magda Floriana. Entendendo o trabalho colaborativo em educação e revelando seus benefícios. Educar. n. 31, p. 213-230, Curitiba: Ed. UFPR, 2008.

FREIRE, Paulo. Pedagogia da autonomia: saberes necessários à prática educativa. 25. ed. São Paulo: Cortez, 2002. 
GIESTA, Nágila Carpolíngua. Cotidiano escolar e formação reflexiva do professor: moda ou valorização do saber docente? $2^{\mathrm{a}}$ ed. Araraquara/SP: Junqueira \&Marin Editores, 2005.

GLAT, Rosana; PLETSCH, Márcia D. ; FONTES, Rejane de S. Educação inclusiva educação especial: propostas que se complementam no contexto da escola aberta à diversidade Educação. Santa Maria, v. 32, n. 2, p. 343-356, 2007.

NORONHA, Eliane Gonçalves; PINTO, Cibele L. Educação especial e educação inclusiva: aproximações e convergências. I Semana de Pedagogia. A formação do pedagogo para a educação do século XXI. Faculdade Católica de Uberlândia. 15-17 julho 2011. Disponível em: $<\mathrm{http}: / /$ www.catolicaonline.com.br/semanapedagogia/trabalhos_completos/ EDUCA $\%$ C3\%87\%C3\%83O $\% 20$ ESPECIAL\%20E\%20EDUCA $\%$ C3\%87\%C3\%83O $\% 20$ INCLUSIVA-\%20APROXIMA\%C3\%87\%C3\%95ES\%20E\%20CONVERG\%C3\%8ANCIAS. pdf $>$. Acesso em mar. 2018.

PERRENOUD, Philippe. Práticas pedagógicas, profissão docente e formação: perspectivas sociológicas. Lisboa : Dom Quixote, 1993.

ZEICHNER, M. Kenneth. Uma análise crítica sobre a "reflexão" como conceito estruturante na formação docente. Educação e Sociedade, Campinas, v. 29, n. 103, p. 535 - 554, maio/ ago. 2008. 